\title{
ANALISIS KEPUASAN PELANGGAN PADA PERUSAHAAN JASA J\&T KOTA BIMA
}

\author{
Atiullah $^{1}$, Ismundar ${ }^{2}$ \\ Program Studi Manajemen, SekolahTinggillmu Ekonomi Bima \\ Jl.Wolter Monginsi Komplek Tolabali, Kota Bima \\ Email: atiullah17.stiebima1@gmail.com
}

\begin{abstract}
Abstrak
Saat ini perkembangan industri jasa pengiriman mengalami peningkatan yang cukup pesat. Era globalisasi menuntut manusia untuk memiliki mobilitas yang tinggi. Salah satu industri jasa yang juga mengalami dinamika dalam pengembangannya adalah jasa pengiriman barang.Dalam ketatnya persaingan usaha jasa pengiriman barang, para pengusaha dituntut melakukan trobosan-trobosan untuk meraih kepuasan konsumennya, diantaranya yaitu dengan dengan menyediakan peningkatan kualitas pelayanan, menyediakan berbagai fasilitas, dan menetapkan harga yang sesuai untuk meraih kepuasan konsumen. Penelitian ini bertujuan untuk mengetahui analisis kepuasan pelanggan pada perusahaan jasa j\&t. Penelitian ini menggunakan pendekatan kuantitatif dengan metode survei, sedangkan jenis penelitian ini termasuk penelitian deskriptif. Populasi dalam penelitian ini adalah konsumen yang pernah menggunakan jasa layanan $\mathrm{j} \& \mathrm{t}$, jumlah sampel yang diambil dalam penelitian ini sebanyak 96 responden. Instrumen penelitian menggunakan angket dengan skala likert. Analisis data yang gunakan adalah uji validitas, uji reabilitas, uji analisis statistik (One-Sample Statistics, One-Sample Test). Untuk menguji pengaruh antar variabel menggunakan SPSS (Statistical Service Product Solutions) versi 23.00. Berdasarkan hasil uji t-test one sampel pada J\&T Kota Bima dikatakan tidak baik karena kurang dari $70 \%$, yang artinya Kepuasan Konsumen pada layanan jasa J\&T belum sesuai dengan keinginan konsumen.
\end{abstract}

Kata Kunci: Kepuasan Pelanggan

Abstract

Currently, the development of the shipping service industry has increased quite rapidly. The era of globalization requires humans to have high mobility. One service industry that is also experiencing dynamics in its development is goods delivery services. In the tight competition in the shipping service business, entrepreneurs are required to make breakthroughs to achieve customer satisfaction, including by providing improved service quality, providing various facilities, and setting prices that are appropriate to achieve consumer satisfaction. This study aims to determine the analysis of customer satisfaction at the $j \& t$ service company. This research uses a quantitative approach with a survey method, while this type of research is a descriptive study. The population in this study are consumers who have used the services of $j \& t$, the number of samples taken in this study were 96 respondents. The research instrument used a questionnaire with a Likert scale. The data analysis used is validity test, reliability test, statistical analysis test (One-Sample Statistics, One-Sample Test). To test the effect between variables using SPSS (Statistical Service Product Solutions) version 23.00. Based on the results of the one-sample t-test on J\&T Kota Bima it is said to be not good because it is less than $70 \%$, which means that customer satisfaction on $J \& T$ services is not in accordance with consumer desires.

Keywords: Customer Satisfaction

\section{PENDAHULUAN}

Seiring dengan perkembangan teknologi digital dan semakin bertambah pula pengguna Smartphone oleh masyarakat yang dibarengi juga dengan fasillitas sosial media maka merubah gaya hidup masyarakat Indonesia dalam berbelanja. Penjualan barang melalui online meningkat pesat dari perubahan gaya hidup ini, karena selain mudah proses nya dan tidak perlu harus datang ketoko, kepasar swalayan untuk mencari barang yang dikehendaki tetapi cukup melalui aplikasi yang adadi smartphone dan bisa mencari barang dan membeli dengan mudahnya, dimanapun mereka berada took online siap mengirimnya. (Prihandoyo,2019)

Persaingan yang terjadi sekarang ini akan membuat pelaku bisnis harus memikirkan strategi yang mampu menarik hati pelanggan sehingga bisa menguasai pasar. Untuk menguasai pasar pebisnis harus menerapkan strategi yang kuat dan akurat agar bisa memenangkan pasar. Pelanggan menjadi faktor penentu dipasar sehinggan mengetahui keinginan dan kebutuhan mereka menjadi hal yang harus dipertimbangkan (Imran \& Ernawati, 2020) 
Produk kreatifitas Indonesia akan kian melesat, platform e-commerce (bisnis digital) bakal semakin marak dengan segmentasi usaha yang beragam dan industri kreatif ini juga makin mendapat tempat dihati konsumen karena tumbuhnya pangsa pasar hingga penyedia layanan jasa logistik atau jasa pengantaran barang ke konsumen. Pertumbuhane-commerce sekarang ini tergolong sangat cepat karena masyarakat sudah menempatkan e-commerce sebagai gaya hidup, bahkan ada yang menganggap kalau tidak berbelanja secara online dinilai ketinggalan jaman (Prihandoyo, 2019).

Semakin tingginya kebutuhan produk jasa ekspedisi sekarang ini memicu munculnya pesaing baru dibidang yang sama dan untuk mempertahankan kepuasan pelanggan maka perusahaan harus memberikan kualitas pelayanan yang baik agar konsumen bisa merasa puas. Pelayanan adalah setiap tindakan atau kegiatan yang dapat ditawarkan oleh suatu pihak kepada pihaklain yang pada dasarnya tidak berwujud dan tidak mengakibatkan kepilikan apapun. Pelayanan merupakan perilaku produsen dalam rangka memenuhi kebutuhan dan keinginan konsumen demi tercapainya kepuasan konsumen. Kepuasan konsumen sangatlah penting untuk mempertahankan loyalitas. (Shandy Widjoyo Putro, 2014).

Pemberian fasilitas memegang peranan penting dalam perkembangan perusahaan pada masa yang akan datang. Karenanya perusahaan jasa perlu memberikan fasilitas yang sebaik-baiknya kepada konsumennya. Tujuan dari fasilitas adalah untuk mencapa itingkat kepuasan konsumen dan diharapkan konsumen akan mau untuk mengulangi lagi membeli jasa yang disediakan oleh perusahaan. Dengan begitu perusahaan telah membentuk suatu kesan yang baik terhadap konsumen sehingga mendorong mereka agar mau berhubungan dengan perusahaan setiap kali mereka membutuhkan jasa yang ditawarkan oleh J\&T Express. (Winarno, 2018).

Pada sisilain, jasa dihadapkan pada kenyataan pelayanan yang berkualitas dan bermutu sehingga terdapat nilai sesuai harapan dan keinginan konsumen. Banyaknya pesaing akan selalu berupaya untuk lebih unggul dari perusahaan dan lebih jauh para pesaing selalu berharap perusahaan keberadaannya tidak langgeng.

Berdasarkan isi latar belakang di atas hubungan jangka panjang dan kerjasama terhadap kinerja operasional perusahaan. Dengan demikian, pentingnya penelitian ini untuk menganalisis lebih dalam mengenai "Analisis Kepuasan Pelanggan Pada Perusahan Jasa J\&T Kota Bima"

\section{TINJAUAN PUSTAKA \\ Kepuasan Pelanggan}

Kepuasan pelanggan adalah tingkat perasaan setelah membandingkan dengan harapannya. Seorang pelanggan jika merasa puas dengan nilai yang diberikan oleh produk atau jasa maka sangat besar kemungkinannya untuk menjadi pelanggan dalam waktu lama (Umar, 2014).

Tjiptono (2011) kepuasan atau ketidak puasan pelanggan adalah respon pelanggan terhadap evaluasi ketidak puasan (disconfirmation) yang dirasakan antara harapan sebelumnya atau harapan kinerja lainnya dan kinerja aktual produk yang dirasakan setelah memakainya. Kuswandi (2013) kepuasan pelanggan yaitu perbedaan antara harapan pelanggan dan persepsi pelanggan terhadap apa yang diberikan perusahaan.

Kotler dan Keller (2012) mengungkapkan kepuasan pelanggan adalah perasaan senang atau kecewa seseorang yang berasal dari perbandingan antara kesannya terhadap kinerja (atau hasil) suatu produk dan harapannya. kepuasan dipengaruhi oleh perbandingan layanan yang dipahami dengan pelayanan yang diharapkan, dan sebagai 
reaksi emosional jangka pendek pelanggan terhadap kinerja pelayanan tertentu. Indikator untuk mengukur kepuasan pelanggan, menurut Yuliarmi dan Riyasa (2013) adalah:

1. Kesesuaian kualitas pelayanan dengan tingkat harapan.

2. Tingkat kepuasan apabila dibandingkan dengan yang sejenis.

3. Tidak ada pengaduan atau komplain yang dilayangkan.

\section{Perumusan Hipotesis Sebagai Berikut :}

Di duga proses pengunaan pada perusahaan jasa j\&t kota bima di atas kriteria yang telah di tetapkan $70 \%$ di terima.

$\mathbf{H}_{\mathbf{0}}$ : Di duga Kepuasan Pelanggan Pada Perusahaan Jasa J\&T Kota Bima Kurang Dari $70 \%$ (ditolak)

$\mathbf{H}_{\mathbf{a}}$ : Di duga Kepuasan Pelanggan Pada Perusahaan Jasa J\&T Kota Bima Ledih Dari $70 \%$ (diterima)

\section{METODE PENELITIAN}

\section{Jenis Penelitian}

Jenis penelitian ini termasuk penelitian deskriptif, yaitu suatu metode dalam penelitian yang dilakukan untuk mengetahui nilai variabel mandiri, baik satu variabel atau lebih (independent) tanpa membuat perbadingan (Sugiyono, 2011:55). Yaitu Analisis Kepuasan Konsumen Pada J\&T Kota Bima.

\section{Definisi Operasional Variabel}

Definisivariabeldapatdijadikansebagallandasanberfikirbagipenelitiuntukmengurai kanataumenjelaskanpermasalahan yang akandiungkapkandenganmenggunakanskalapengukuranLikert.

Olehkarenaitupenelitimengemukakandefinisivariabel, yaitu :

Kepuasan Konsumen $(\mathbf{X})$ adalah keadaan senanang atau kecewa yang dialami oleh seorang konsumen setelah dia menikmati pelayanan yang rasakan.

\section{UjiValiditasdanUjiReabilitas}

a. UjiValiditas

Menurut Sugiyono (2016:177) menunjukkan derajat ketepatan antara data yang sesungguhnya terjadi pada objek dengan data yang dikumpulkan oleh peneliti untuk mencari validitas sebuah item, Suatu variabel dikatakan valid jika memiliki nilai $\mathrm{r}$ hitung $>0$, 300. Pengujian validitas ini dihitung dengan menggunakan bantuan dari Program SPSS.

b. UjiReliabilitas

Menurut Imam Ghozali (2013) Reliabilitas berhubungan dengan kepercayaan masyarakat. Reabilitas merupakan alat untuk mengukur suatu daftar pertanyaan koisioner yang merupakan indikator dari variabel-variabel yang diteliti. Suatu variabel dikatakan reliable (handal) jika memiliki nilai Cronbach Alpha $>0,600$. Pengujian relibilitas ini dihitung dengan menggunakan bantuan dari Program SPSS.

\section{AnalisaStatistik}

Data yang telah didapatkan dalam penelitian ini akan dianalisis dengan menggunakan analisis t-test satusampel. 


\section{HASIL PENELITIAN}

\section{Uji Validitas dan Uji Reliabilitas}

a. Uji Validitas

Tabel 1.HasilUjiValiditas

\begin{tabular}{llll}
\hline Variabel & R Hitung & Nilai Batas & Keterangan \\
\hline Xp1 & 0,587 & 0,300 & Valid \\
Xp2 & 0,719 & 0,300 & Valid \\
Xp3 & 0,524 & 0,300 & Valid \\
Xp4 & 0,509 & 0,300 & Valid \\
Xp5 & 0,464 & 0,300 & Valid \\
Xp6 & 0,412 & 0,300 & Valid \\
Xp7 & 0,713 & 0,300 & Valid \\
Xp8 & 0,614 & 0,300 & Valid \\
\hline
\end{tabular}

Sumber : Data Primer diolah SPSS v. 23, 2021

Berdasarkan tabel 1 di atas, hasil pengujian validitas variabel Kepuasan Pelanggan dapat dikatakan valid pada Corrected item-total correlation >0,300. Hasil pengujian validitas ini menunjukkan bahwa pernyataan kuesioner dalam penelitian ini valid.

\section{b. Uji Reliabilitas}

Tabel 2.Hasil Uji Reliabilitas

\begin{tabular}{llll}
\hline Variabel dan Indikator & $\begin{array}{l}\text { Cronbach's } \\
\text { Alpha }\end{array}$ & $\begin{array}{l}\text { Standar } \\
\text { Reliabilitas }\end{array}$ & Keterangan \\
\hline Variabel Kepuasan Pelanggan & 0,706 & $>0,600$ & Reliabel \\
\hline
\end{tabular}

Sumber : Data Primer diolah SPSS v. 23, 2021

Hasil pengujian penelitian menggunakan pengukuran ini dapat dikatakan reliabel pada Cronbach alpha> 0,600. Hasil pengujian reliabilitas ini menunjukkan bahwa pernyataan quesioner dalam penelitian ini reliabel.

\section{One-Sample Statistics}

Tabel3.One-Sample Statistics

One-Sample Statistics

\begin{tabular}{lllll}
\hline & N & Mean & $\begin{array}{l}\text { Std. } \\
\text { Deviation }\end{array}$ & $\begin{array}{l}\text { Std. } \\
\text { Mean }\end{array}$ \\
\hline KepuasanKonsumen & 96 & 35.71 & 3.761 & .384
\end{tabular}

Sumber : Data Primer diolah SPSS v. 23, 2021

Tabel one-sample statistics di atas menunjukan nilai statistik deskriptif, yaitu $\mathrm{N}$ = 96 artinya jumlah sampel yang di pakai adalah 96 responden. Mean = 35,71 artinya nilai rata-rata hitung adalah 35,71. Std. Deviation atau simpangan baku adalah sebesar 3,761. Dan Std. Error Mean adalah sebesar 0,384. 


\section{One-Sample Test}

Tabel4.One-Sample Test

One-Sample Test

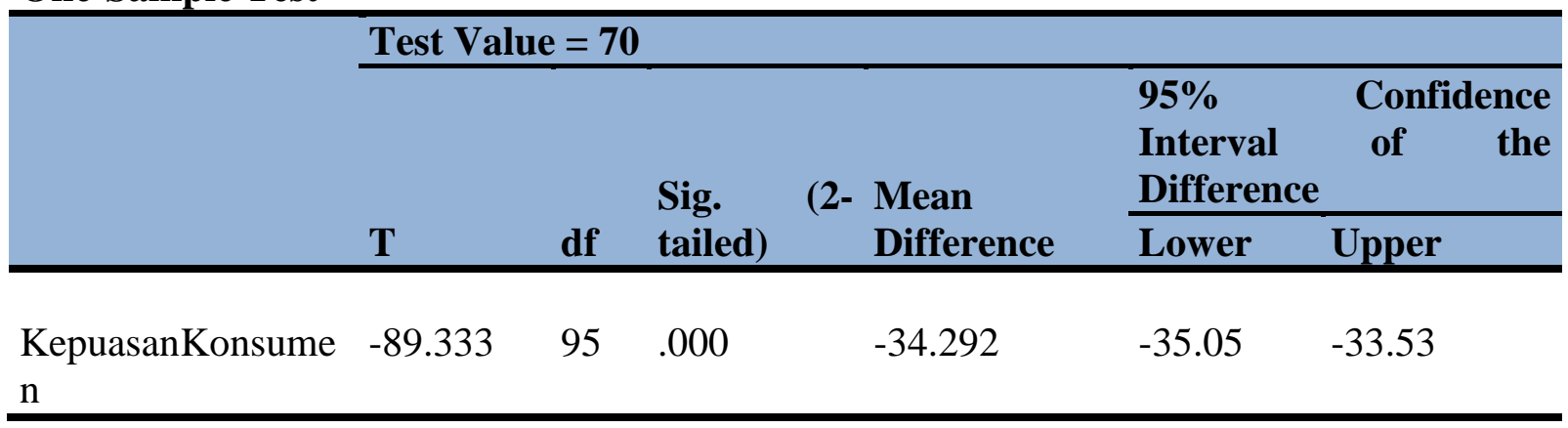

Sumber : Data Primer diolah SPSS v. 23, 2021

Berdasarkan dari total diatas dapat diketahui $t_{\text {hitung }}-89,333$ dari $t_{\text {tabel }} 1,66105$, maka $t_{\text {hitung }}<\mathrm{t}_{\text {tabel }}(-89,333<1,66105)$ berarti terjadi penerimaan $\mathrm{H}_{0}$ yaitu kepuasan pelanggan pada perusahaan J\&T Kota Bima kurang dari 70\% ditolak.

\section{KESIMPULAN DAN SARAN}

\section{Kesimpulan}

Berdasarkan hasil uji t-test one sampel pada J\&T Kota Bima dikatakan tidak baik karena kurang dari $70 \%$, yang artinya Kepuasan Konsumen pada layanan jasa J\&T belum sesuai dengan keinginan konsumen.

\section{Saran}

Untuk peneliti selanjutnya diharapkan agar dapat memperluas cakupan penelitian dengan menambahkan variabel lain, baik variabel seperti kualitas pelayanan dan lainlain.

\section{DAFTAR PUSTAKA}

Anri Citra Annisa, Marheni Eka Saputri,S.T.,M.B. Analisis Kepuasan Konsumen Berdasarkan Kualitas Pelayanan Menggunakan Metode Importance Performance Analysis (Studipada Perusahaan J\&T Express di Bandung). eProceeding of Management : Vol.7, No.1 April 2020. ISSN : 2355-9357

C. Prihandoyo, 2019. Pengaruh Kualitas Pelayanan Terhadap Kepuasan Pelanggan JNE Cabang Balikpapan. Jurnal GeoEkonomi ISSN-Elektronik (e): 2503-4790 | ISSN-Print (p): 2086-1117 http://jurnal.fem.unibabpn.ac.id/index.php/geoekonomi

Imran \& Ernawati sri, (2020). Pengaruh Logistik Servic E Quality Terhadap Kepuasan Konsumen Pada Produk Cv Cahaya Mulia Di Kota Bima. Pelita ( Jurnal penelitian dan karya ilmiah) Vol. 20 No. 2, Hal 125-131

Kotler, Philip danAmstrong, Gary, (2016), Principles of Marketing, 15th Pearson, Education Limited

Kotler, Philip dan Keller, Kevin Lane, (2016), Marketing Management, 15th Edition, Pearson Education Limited

Sugiyono, Prof., Dr. (2010). StatistikaUntukPenelitian. Bandung :Alfabeta, CV 3. 
Sugiyono, Prof., Dr. (2012). MetodePenelitianKuantitatifKualitatifdan R\&D. Bandung :Alfabeta, CV

S.Winarno.,L.Mananeke.,I.W.J.Ogi,. AnalisisPelayananKonsumen Dan FasilitasTerhadapKepuasanKonsumenKedai Kopi Maxx Coffee Cabang Hotel Aryaduta Manado. Jurnal EMBA Vol.6 No.3 Juli 2018, Hal. 1248 - 1257

Tjiptono, Fandy.,Gregorius Chandra. (2011). Service, Quality, \& Satisfaction, Edisi 3 Yogyakarta: Andi.

Johan Oscar Ong, JatiPambudi.AnalisisKepuasanPelangganDengan Importance Performance Analysis Di Sbu Laboratory CibitungPtSucofindo (Persero). J @TI Undip, Vol IX, No 1, Januari 2014. 